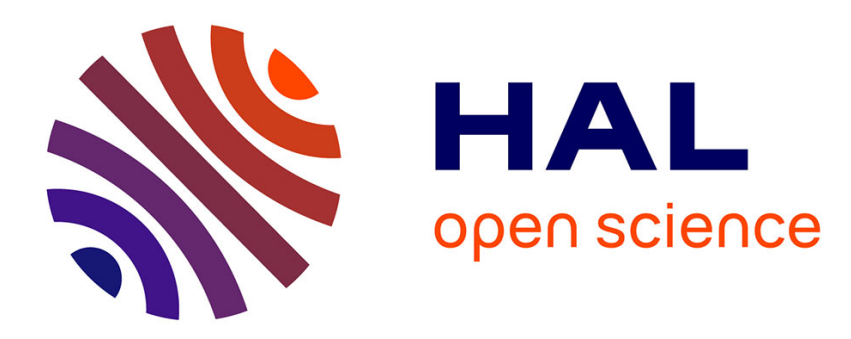

\title{
Use of Mode Stirred Reverberating Chambers for evaluating wireless communication performances
}

Wilfrid Quenum, Isabelle Junqua

\section{To cite this version:}

Wilfrid Quenum, Isabelle Junqua. Use of Mode Stirred Reverberating Chambers for evaluating wireless communication performances. 2018 Asia-Pacific Microwave Conference (APMC2018), Nov 2018, KYOTO, Japan. hal-01948471

\section{HAL Id: hal-01948471 \\ https://hal.science/hal-01948471}

Submitted on 7 Dec 2018

HAL is a multi-disciplinary open access archive for the deposit and dissemination of scientific research documents, whether they are published or not. The documents may come from teaching and research institutions in France or abroad, or from public or private research centers.
L'archive ouverte pluridisciplinaire HAL, est destinée au dépôt et à la diffusion de documents scientifiques de niveau recherche, publiés ou non, émanant des établissements d'enseignement et de recherche français ou étrangers, des laboratoires publics ou privés. 


\title{
Use of Mode Stirred Reverberating Chambers for evaluating wireless communication performances
}

\author{
Wilfrid Quenum ${ }^{1}$, Isabelle Junqua ${ }^{1}$, \\ ${ }^{1}$ ONERA/DEMR, Université de Toulouse, F-31055 Toulouse-France, wilfrid.quenum@onera.fr
}

\begin{abstract}
In wireless communication, channel propagation prediction is sometimes difficult especially in confined metallic space due to the fast fading and multipath complexity. Wireless system deployment on aircraft and other vehicles seems to be nowadays unavoidable but some concerns remain about the reliability and security of critical and real-time communications. This paper presents the opportunity given by the Mode Stirrer reverberating Chamber (MSRC) to develop and test a wireless communication system in a multipath propagation environment. The controllable and repeatable statistical characteristics of a MSRC studied here by the measurement of transfer functions (TF) in the frequency domain make it possible to define and also emulate Rayleigh propagation channel. Modified $Q$ factor by loading the cavity can change the RMS delay spread and the canal selectivity in order to reproduce representative propagation paths, as the one measured in an aircraft.
\end{abstract}

Key words: Wireless communication; Transfer functions, Mode Stirred Reverberating Chambers, MSRC, EMC

\section{CONTEXT}

Wireless systems are nowadays unavoidable in all system and their exploitation is drastically simplified. In this context aeronautic is interested in taking advantage of these technological breakthroughs. Of course the first aim is to reduce the weight and fuel consumption by decreasing embedded network cables architectures. Another interesting trend concerns the flexibility provided by the wireless system for maintenance access. Also, the wireless networks sensors implementation seems to become essential to collect a multitude of physical data for the airplane diagnosis and structural information. Nevertheless reliability and security mandatory for real-time or critical communication in aircraft require strong tests validation. The diversity of standards currently used in the unlicensed ISM frequency bands implies the coexistence between the various systems. In order to overcome this difficulty ITU [1] has defined a frequency band specifically dedicated to intra communications in aircraft (WAIC - 4.2-4.4GHz) and has specified the operating rules.

Nevertheless coexistence of wireless systems is necessarily a matter of electromagnetic compatibility (EMC); in order to ensure safety, security and signal integrity, those wireless communications systems, must of course comply with classical EMC requirement and standards [2].
Estimating and optimizing the quality of data transmission in a wireless communication service implies a realistic knowledge of the propagation channel characteristics which can be, as a first step, reduced to two key features which are the attenuation of the propagation path and the RMS delay spread $\left(\tau_{\mathrm{RMS}}\right)$ or coherence bandwidth $\left(\mathrm{B}_{\mathrm{c}}\right)$.

Mode Stirring Reverberating Chambers (MSRC), initially developed for Electromagnetic Compatibility (EMC) seem to be a good candidate to evaluate the performance of wireless systems under development in typical propagation channels and especially for indoors applications ([3] [4] [5]).

As a first step, section II reports on some measurements of propagation channel characteristics carried out in a Falcon 20 aircraft in order to later on define a wireless intracommunication system. As a second step, it is shown how a multi-cavity mode stirred reverberating structure can be used in order to reproduce representative propagation path as the ones measured in the aircraft.

\section{CHARACTERIZATION OF PROPAGATION PATH IN A FALCON20 AIRCRAFT}

Some experiments were performed in a Falcon20 aircraft lent by AVDEF company in order to acquire representative and typical complex propagation path features in an aircraft (Figure 1).

The experimentation consisted in measuring conventional broadband transfer function (TF) between a transmitting and a receiving antennas in magnitude and phase via a network analyzer and S-parameter techniques. Antennas were placed in various main bays of the aircraft, distributed at the front (cockpit), middle (cabin) and rear of the aircraft (APU and rear bays).

In order to simulate different possible locations of installation of transmission and reception components inducing fluctuations of the propagation channel, a mechanical stirrer has been introduced in aircraft compartments. Consequently, as in MSRC, the transfer function was acquired for each position of the stirrer. 

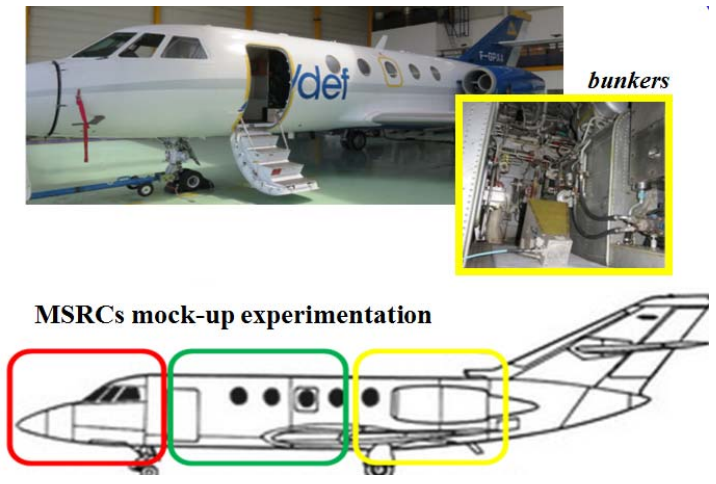

Figure 1 : Falcon20 Aircraft - Instrumentation

The resulting attenuations measured for different locations of the transmitting and receiving antennas and averaged over a stirrer rotation are plotted between $1 \mathrm{GHz}$ and $6 \mathrm{GHz}$ in Figure 2. These results put to the fore typical features in the whole frequency band. In the frequency band dedicated to WAIC between $4.2 \mathrm{GHz}$ and $4.4 \mathrm{GHz}$, one can note attenuations:

- around -35 and $-30 \mathrm{~dB}$ when transmission/reception are in the same or close to each other small confined bays (as in rear bay and in APU bay),

- around -50 and $-40 \mathrm{~dB}$, when transmission/reception are in large open cavities as in cockpit and in cabin,

- around -80 and $-75 \mathrm{~dB}$, when transmission/reception are far from each other and separated by multiple cavities.

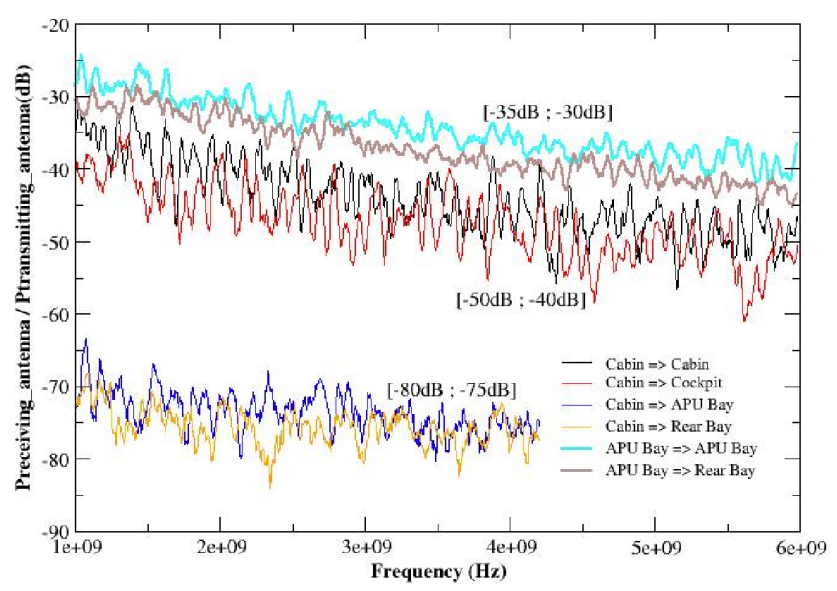

Figure 2 : Aircraft frequency propagation path

The frequency domain measurements can be postprocessed in the WAIC bandwidth in order to obtain the impulse response of the propagation channel and the RMS delay spread. As an example, these impulse responses computed for a propagation channel between the cabin and the rear bay are plotted in Figure 3 for different positions of the stirrer in order to reproduce natural fluctuations of the channel.

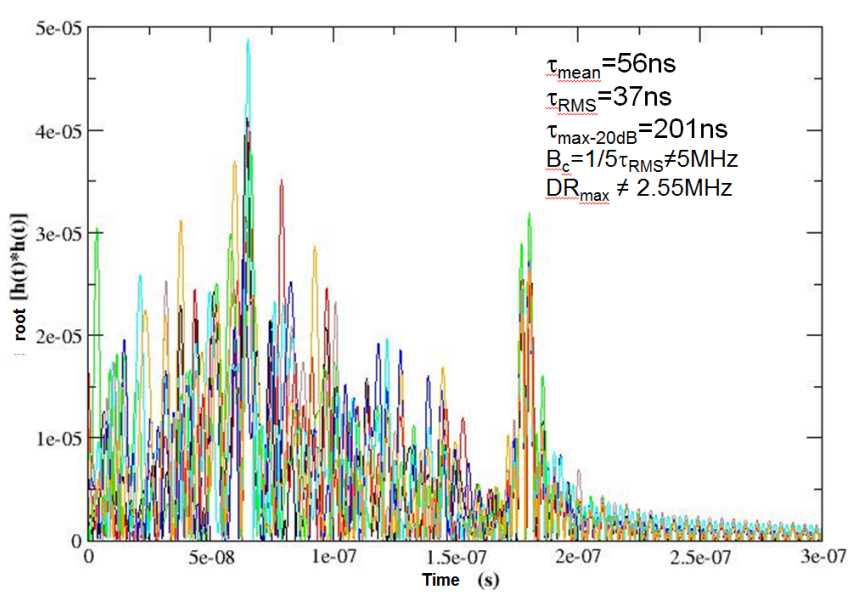

Figure 3 : Impulse response of the propagation channel between the cabin and the rear bay in WAIC bandwidth and resulting RMS time delay spread

\section{USE OF A MULTI CAVITY MODE STIRRING REVERBERATION CHAMBER TO EMULATE PROPAGATION CHANNEL}

\section{A. MSRCS characteristic and multipath environment}

In order to simulate a confined environment as in an aircraft or in a vehicle, we used a metallic parallelepiped structure made of three connected elementary cavities $(1 \mathrm{x}$ $0.9 \times 0.70 \mathrm{~m}^{3}$ ) which could represent the front, middle and rear parts of the aircraft. Some walls with aperture can be inserted between the three cavities in order to obtain smaller interconnected inner volumes and to artificially increase the attenuation of the propagation channel. It is equipped with a step-by-step stirrer located on one of the 3 cavities as illustrated in Figure 4.

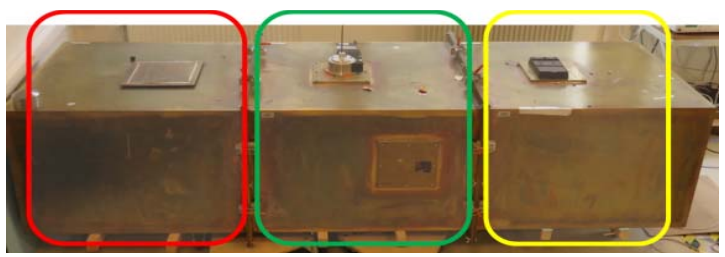

Figure 4: MSRC; The three reverberating cavities and the stirrer electrical motor on the top side of one cavity

The MSRC measurement system is illustrated in Figure 5:

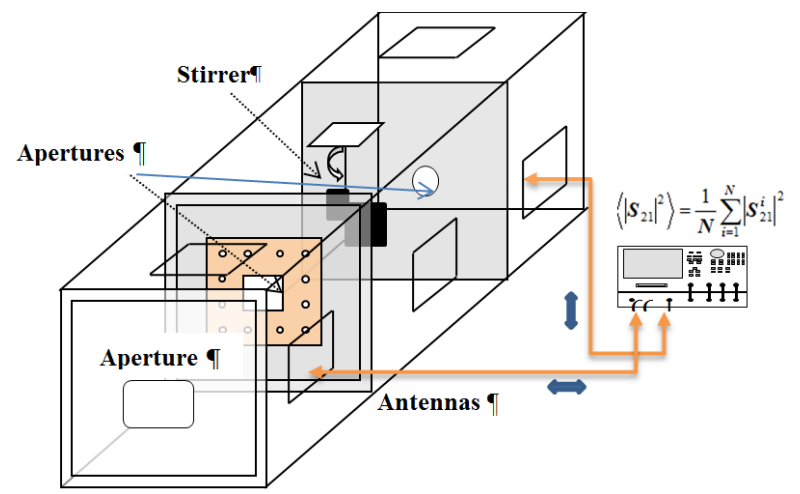

Figure 5 : MSRC \& intermediate separation area 
Principal advantage of the MSRCs is the ability to generate a reproducible and controllable Rayleigh statistical environment [4] over a complete rotation of the stirrer placed in the cavity; but also emulate independent series of propagation channels as in Figure 6 under Q quality factor control [5].

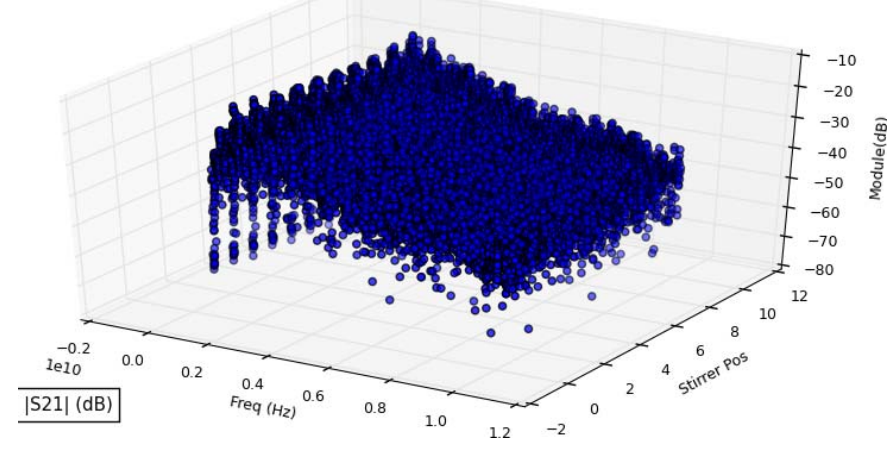

Figure 6 : Channel path profile Vs Stirrer position \& frequency

\section{B. Aircraft and MSRC, propagation channel comparison}

The 3-cavities MSRC structure can be configured by inserted absorbers or interfaces with calibrated hole in order to obtain equivalent levels of attenuation as previously measured in the aircraft. An example is given in Figure 7. Note that after $4 \mathrm{GHz}$ the propagation channel measured in the aircraft is not significant due to a non negligible noise level. Nevertheless, one can assume that electromagnetic phenomena present continuous fluctuations versus frequency.

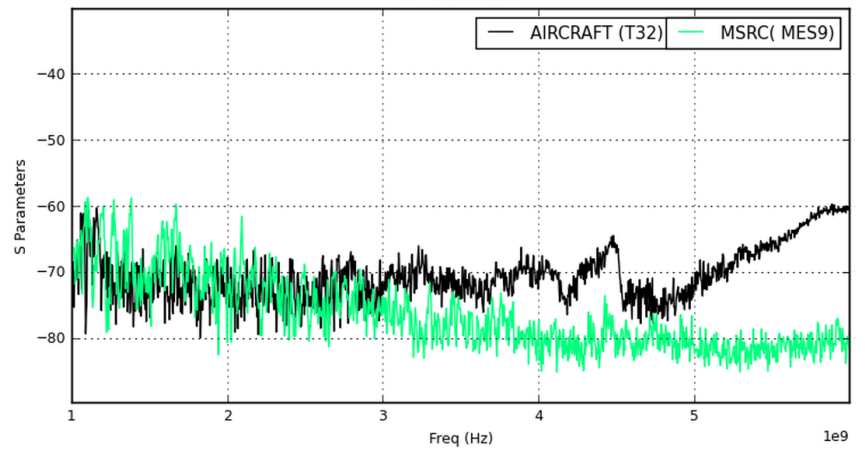

Figure 7 : Path Loss Aircraft Cabin-Rear and loaded MSCR structure

These results are very hopeful because we will be able to easily test various propagation channel scenarios in MSRC and assess the transmission performances of wireless systems before real implementation on aircraft. Additional examples will be given in the final paper.

It has been shown in [6] that the RMS delay spread $\left(\tau_{\mathrm{RMS}}\right)$ is proportional to the chamber Q-factor for a given frequency; and similarly the corresponding band of coherence $\mathrm{B}_{\mathrm{c}}$ is inversely proportional to the quality factor. Figure 8 shows how the Q-factor of the multi-cavity MSRC structure can be adjusted by adding calibrated absorbers in the cavity to obtain pre-defined coherence bandwidth and RMS delay spread.

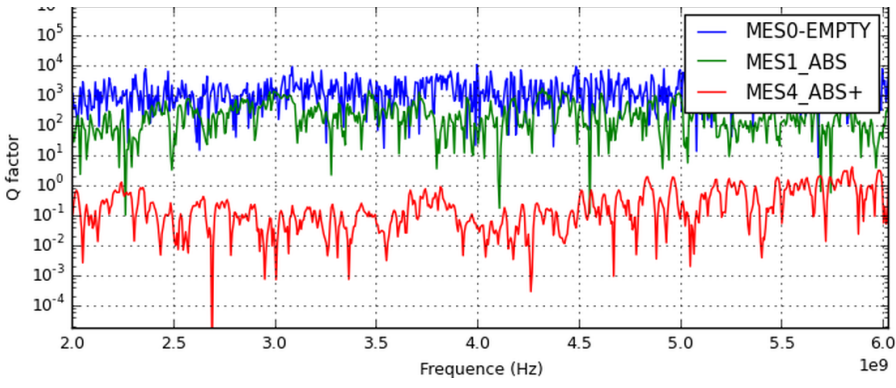

Figure 8 : Cavity Q-factor gradually loaded (mes1\&4)

\section{CONCLUSION}

In this preliminary work, through the experimental evaluation of realistic propagation channel carried out in an aircraft, we have shown the significant contribution of MSRC multi-cavities to characterize and easily emulate different random and independent propagation channels by controlling the Q-factor and consequently the RMS delay spread. This original approach can help to pre-design and optimize wireless systems through preliminary tests of link performance in multipath and confined controlled in-lab environment.

Further investigation will consist in evaluating the use of flexible Software Define Radio (SDR) for testing a basic transmission wireless system inside the MSRC and implementing additional characteristic like noise and interference considerations.

\section{REFERENCE}

[1] ITU International Telecommunication Union, "Use of wireless avionics intracommunications in the frequency band 4200-4400 MHz," Nov. 2015

[2] IEC 61000-4-21: Electromagnetic compatibility \& IEE $802.11 \mathrm{a} / \mathrm{g}$, IEEE Wireless Local Area Networks

[3] E. Genender(1,2), C.L. Holloway(2), K.A. Remley(2), J. Ladbury(2), G. Koepke(2) and H. Garbe, "Use of Reverberation Chamber to Simulate the Power Delay Profile of a Wireless Environment" 2008 IEEE

[4] C. L. Holloway, D. A. Hill, J. M. Ladbury, P. F. Wilson, G. Koepke, , and J. Coder, "On the use of reverberation chambers to simulate a rician radio environment for the testing of wireless devices, " IEEE transactions on antennas and propagation, 2006

[5] Hope D., J. Dawson, A. Marvin, M. Panitz, C. Christopoulos, and P. Sewell, "Assessing the performance of ZigBee in a reverberant environment using a mode stirred chamber," IEEE, Aug. 2008

[6] O. Delangre, Ph. De Doncker, M. Lienard and P. Degauque "Delay spread and coherence bandwidth in reverberation chamber" , Electronics Letters 28th February 2008

[7] N. R. Díaz, and J. E. J. Esquitino, "Wideband channel characterization for wireless communications inside a short haul aircraft," in Proc. May 2004 